\title{
A PATT Study Among 10 to 12-Year-Old Students in The Netherlands
}

\author{
Falco de Klerk Wolters ${ }^{1}$
}

\section{Introduction}

Education in technology is behind the fast technological changes of the last decade. In the Netherlands, as in many other countries, technology is being introduced as a separate subject to overcome this back-log. The subject is required for all 12 to 15-year-olds. Also, in primary education (age 4 to 12) there is a growing interest in teaching about technology.

It is important to take into account pupils' interests, opinions and needs when developing technology curricula. It is also important not to rely only on the subject-centered approach derived from technology experts. Boys' and girls' differences in attitudes towards technology, for example, can put girls at a disadvantage when they choose a career. (Rennie 1988).

This "student-centered approach" is characteristic of the international Pupils' Attitudes Towards Technology (PATT) project. (Mottier, 1986; Todd, 1986). Compared with studies about pupils' attitudes towards "science" or "science and technology," not much literature is devoted to attitudes towards technology as a general concept. Raat and de Vries started PATT in 1986 with the purpose of developing an instrument that could be used internationally to measure pupils' attitudes towards technology. Researchers in 11 countries conducted pilot studies with translated questionnaires. From these results, an instrument was developed that was proved to be reliable and valid in the Western countries (Raat, de Klerk Wolters, de Vries 1989). The instrument has now been used in many countries all over the world, including Australia, Belgium, Canada, Denmark, France, Hungary, India, Italy, Kenya, Nigeria, Mexico, Poland, Great Britain, the United States, Surinam, Sweden and Zimbabwe.

This article describes a large scale measurement in the Netherlands among 10 to 12-year-old students in grades 7 and 8 of the primary school. The attitudes towards technology of two other age groups, 13 to 15 -year-olds and 16 to 18-year-olds, have already been investigated and an integration of the results of the three cross-sectional studies is in preparation by the author.

\section{Literature Review}

At the age of 10, pupils already have ideas about technology and it seems that they have already developed attitudes towards technology. Boys seem to have a more positive attitude towards technology than girls. However, there is little research available to support these assumptions.

Smail and Kelly (1984) did an extensive study among this age group. They used three instruments to measure attitudes towards science and technology: a Science Curiosity Test, a Science Activity Scale and an Image of Science Test. Their results show that at the age of 11, the attitude towards science and technology of boys and girls differs more greatly than the cognitive differences between boys and girls. Boys have a more positive attitude towards technology than girls. Also, boys are more interested in subjects related to physics and girls are more interested in biological subjects. Moore (1987a, 1987b) used drawings and developed a Technology Picture Questionnaire (TPQ) to investigate pupils' ideas about technology. He used drawing methods because young pupils may not have the writing and reading skills needed for written tests. From the drawing analyses, it appears that boys and girls associate technology with "making something." The products they draw differ: boys mainly draw "transportation" and "computers" and girls draw "electrical equipment in general." Pupils believe that a "technologist" is a "scientist," doing "difficult things." The TPQ, which is based on the results of the drawing analysis, consists of drawings of people who are working. A caption below each drawing explains what the person is doing. Pupils must indicate whether an activity is technical or not. The results of the TPQ show that young pupils associate technology with "inventing," "making," and "working with electricity." Criteria they use to

1 Falco de Klerk Wolters is Researcher, Eindhoven University of Technology, The Netherlands. 
distinguish the "technical" from the "non-technical" are: "difficulty," "high-tech" and "relevance." For example, repairing a chairleg (not difficult) and developing a tomato sauce (not relevant) are considered to be non-technical. No significant differences between boys and girls were found in the use of these criteria.

From attitudes towards science studies, it might be possible to deduce some predictors for attitudes towards technology. Meta-analyses of research on attitudes towards science from Gardner (1975) and Schibeci (1984) show that "sex," "personality" (self-concept) and "school" (class behavior) are important predictors for attitudes towards science. Educational variables like "achievement" and "intelligence" have a weak influence on attitudes towards science. The same applies to structural variables like "grade level" or "socio-economic background." A possible predictor of attitudes towards technology is "familiarity with technology." Knulst and Van Beek (1988) found that this variable is rather important in explaining the attitude towards technology among adults.

\section{Methodology}

\section{Research Questions}

The study focused on two questions:

1. What is the concept of and the affection towards technology of 10 to 12 -year-old pupils?

2. Which variables affect attitudes towards technology?

\section{Population and Sample}

The total population of 10 to 12 -year-olds consists of about 50,000 pupils belonging to 8,000 primary schools in the Netherlands. The sample consisted of 2,050 pupils belonging to 60 schools. This sample was representative of the whole population with respect to sex, geographical variations and schooltypes. To fulfill statistical requirements for an independent random sample, 900 pupils should have been required. But a larger sample was necessary because the sample consisted of whole school classes.

\section{Instrumentation}

The attitude towards technology is multi-dimensional. This is reflected in the instrument. It consists of 6 scales measuring the Affective and Behavioral components of the attitude towards technology (so called AB-scales) and 4 scales measuring the Cognitive component of the attitude toward technology (so called C-scales). The AB-scales are: a) Interest - the extent to which pupils engage in technological activities outside school; b) Role pattern - the extent to which technology as a career or study is equally suitable for boys and girls; c) Consequences - the extent to which pupils think that the effects of technology are negative; d) Difficulty - the perceived difficulty of technology as a school subject or a profession; e) School - the extent to which pupils like technology as a school subject; and f) Career - the extent to which pupils like technology as a profession.

The C-scales are: a) Society - technology is directed and controlled by human beings; b) Science - there exists a mutual influence between technology and science; c) Skills - technology has to do with skills; and d) Pillars - matter, energy and information are the pillars of technology.

The AB-scales are based on opinions and statements of pupils themselves about technology. The C-scales were designed a priori and operationalize a definition of technology in which technology is described by five features: a) technology is a feature of human activities; b) matter, energy and information are the "pillars" of technology; c) there is a mutual influence between technology and sciences; d) the three most important skills in technology are design skills, practical-technical skills (making, producing), and skills in handling (using) technical products; and e) there is a mutual influence between technology and society (Raat and de Vries, 1986).

The AB-scales are based on the Likert scale model. Pupils had to answer on a 5-point answering format: "totally agree," "agree," "not agree/not disagree," "disagree," "totally disagree." The C-scales are based on a probabilistic Guttman scale model (Mokken 1970). Pupils had to answer a 3-point answering format: "agree," "disagree," and "don't know."

Two different methods were used to answer the research questions: 1) written questionnaires, including the ABC-scales; and 2) drawings of technology and semi-structured interviews about technology.

Written questionnaires were supposed to measure the attitude towards technology. Two C-scales "Science" (relation technology science) and "Pillars" (matter, energy and information) were not used because they were not relevant and too difficult for 10 to 12-year-olds (see Table 1).

The alpha-values of the AB-scales were reasonable, but the $\mathrm{H}$-values of the C-scales were too low. Therefore, the decision was made to also use alternative methods - drawing and interviews - to investigate pupils' concept of technology. Fifteen students from three teacher training colleges, doing their practical 
Table 1

Scale Names, Typical Items and Reliability Values

\begin{tabular}{|c|c|c|}
\hline AB-Scales & Typical Item & Cronbach-Value \\
\hline $\begin{array}{l}\text { INTEREST } \\
5 \text { items }\end{array}$ & $\begin{array}{l}\text { I like to read technological } \\
\text { magazines }\end{array}$ & .78 \\
\hline $\begin{array}{l}\text { ROLE PATTERN } \\
4 \text { items }\end{array}$ & $\begin{array}{l}\text { Typical item: A girl can } \\
\text { have a technical job }\end{array}$ & .70 \\
\hline $\begin{array}{l}\text { CONSEQUENCES } \\
5 \text { items }\end{array}$ & $\begin{array}{l}\text { Technology has brought more good } \\
\text { than bad things }\end{array}$ & .59 \\
\hline $\begin{array}{l}\text { DIFFICULTY } \\
3 \text { items }\end{array}$ & $\begin{array}{l}\text { Technology is only for bright } \\
\text { people }\end{array}$ & .60 \\
\hline $\begin{array}{l}\text { SCHOOL } \\
3 \text { items }\end{array}$ & $\begin{array}{l}\text { I would like to learn more about } \\
\text { technology at school }\end{array}$ & .81 \\
\hline $\begin{array}{l}\text { CAREER } \\
5 \text { items }\end{array}$ & $\begin{array}{l}\text { I would like to have a job in } \\
\text { technology some day }\end{array}$ & .80 \\
\hline C-Scales & Typical Item & H-Value \\
\hline $\begin{array}{l}\text { SOCIETY } \\
8 \text { items }\end{array}$ & Technology is as old as mankind & +.25 \\
\hline $\begin{array}{l}\text { SKILLS } \\
4 \text { items }\end{array}$ & In technology you handle tools & +.33 \\
\hline
\end{tabular}

year, did this part of the research. These students were given extensive training for this purpose by the author in order to learn about the definition of technology and attitude measurement.

The student teachers had to categorize all the elements of drawings made by their class into the following groups: products, process, evaluation, place indication, and fantasy. For each group the interrater reliability or Kappa coefficient was calculated (Cohen 1980). One group had a low coefficient (R(it) evaluation=.51), others have coefficients $>.65$.

Interviews were held with 60 boys and 60 girls. The interviews were semi-structured, refering to the five features of technology (C-scales) and also to the AB-scales.

To investigate potential predictors of the attitudes towards technology, a series of questions (in the written questionnaire) had to be answered. These questions operationalized the following variables: Sex, School Choice (vocational or general school), School Experience (like school or not), Self-Concept (perceived knowledge of technology), Ambition (future technical or non-technical career), Home Environment (technical or non-technical profession of parents, technical or non-technical brothers and/or sisters, technical or non-technical friends, amount of technical tools, played with technical toys or not), and Teacher Attitude (attitude of the classroom teacher towards technology).

\section{Data-collection and Analyses}

Written questionnaires were filled in at schools during schooltime. The class teachers were given instructions, and had to fill in a questionnaire themselves to measure their own attitudes towards technology. The questionnaires were returned to Eindhoven University of Technology and an SPSS data matrix was developed from the results. The data were analyzed by means of SPSSx and SPSSpc+. Standard statistical programs were used: Reliability, Factor, Regression, Pearson Correlation, Partial Correlation, T-Test, Nonparametric Correlation, Oneway ANOVA. In addition, the student teachers recorded the interviews on tape and collected the elements of the drawings in data-matrices. 


\section{Results/Findings}

Affective and Behavioral Aspects

As was the case with older age-groups, 10 to 12-year-olds had positive attitudes towards technology. The scores on the AB-scales are positively skewed (see Figure 1).

Figure 1. Comparing Boys and Girls on AB-Scales

Boys scored significantly higher on the positive attitude scales than girls $(\mathrm{p}<.001)$. The largest differences were on the scales Interest, School, and Career. Boys liked technology more than girls did, boys wanted to hear about it at school more than girls, and more boys than girls wanted to have a technical profession in the future. These differences in interest were also found in the interviews. Boys were, in particular, focused on "equipment- technology." The operating of and playing with computers and other electric equipment was more normal for boys than for girls. The differences between boys and girls on other attitudinal aspects of technology (Role Pattern, Consequences and Difficulty) were less extreme. Boys considered technology to be more important than girls. From the interviews, it became evident that this was not a consequence of girls thinking in a more differentiated way, as was suggested by Grant and Harding (1987). On the question "Is technology good or bad?" more boys than girls mentioned the bad sides of technology (35.0\% of the boys versus $18.3 \%$ of the girls). In contrast with the scores on the Difficulty scale, $45 \%$ of the boys and $76.6 \%$ of the girls considered technology to be difficult. Only $5 \%$ of the boys and $1 \%$ of the girls believed that technology is easy.

\section{Concept of Technology}

Boys scored significantly higher on the two C-scales than girls (see Figure 2). The boys' and girls' concept of the relation "technology and skills" is reasonable, whereas the scores on the Society-scale sugggest that the concept of the relation "technology and society" was poor. It means that pupils are not aware of the daily influence of technology on their lives. This finding corresponds with the findings from the drawing analyses and the interviews. 
Figure 2. Comparing Boys and Girls on C-Scales

In the drawings, a great many "daily products" can be found (see Table 2). But these drawing are usually without human beings. This may be because people are more difficult to draw than computers, but it is more likely that pupils do not think of human beings in relation to technology. According to the student teachers, their pupils liked talking about technology and they also had fun drawing about technology. This confirms the assumption that pupils at the age of 10 already have ideas and conceptions about technology. Their first association with technology is products - mainly electrical products like computers, radio, television and $\mathrm{CD}$ players. On the question of whether they think about equipment or human beings when thinking about technology, only $8.3 \%$ of the boys and $16.7 \%$ of the girls thought of human beings. Many boys (53.3\%) and girls (78.3\%) believed that they have nothing to do with technology. As a matter of fact, many boys (50.0\%) and girls $(71.7 \%)$ had the perception that a lot of people were not dealing with technology. The kind of people that they mentioned were babies, young children (like themselves), unemployed people, old people (senior citizens), people from the developing countries, mothers, and (unfortunately) also teachers. It is striking to note that $40.0 \%$ of the girls could not mention one technical profession, whereas this percentage is much lower for boys $(3 \%)$.

Another misconception of 10 to 12-year-olds in the Netherlands is the association of technology with something modern $(23.3 \%$ boys and $45.0 \%$ girls). A relatively high percentage (10.0\% boys and $40.0 \%$ girls) were not able to mention school subjects that are related to technology. When they did, they mentioned arithmetic and math, but not "knowledge of nature" and "biology" (which are both taught at primary school).

Most boys (81.7\%) and girls (74.1\%) agreed that inventing, doing things with your hands and repairing are part of technology. However, they considered repairing a bike an inferior technological activity to working with a computer.

The conclusion is that boys, and to a lesser extent girls, have a positive feeling (affection) towards technology, but that their concept of technology is rather poor.

\section{The Influence of Variables on the Attitude Towards Technology}

Already at the age of 10, we can notice extreme differences between boys and girls in their attitudes towards technology. As pupils grow older, these differences do not seem to disappear (de Klerk Wolters, 1989). Probably the attitudes towards technology, which are formed at an age younger than 10, are very persistent and may be more resistant to change than we expect. Gender is an important predictor of attitudes towards technology, as it is in predicting attitudes towards science.

The influence of variables related to school was weak (see Table 3). The school choice did not predict the attitudes towards technology. There was no significant difference between pupils who say they want to go to a vocational school and those who say they will go to a general education school. There was also no significant difference between pupils with positive (like school) and negative (do not like school) school experiences. Finally, there was only a vague (insignificant) relationship between the teachers' attitudes towards technology (measured with a separate instrument) and the class' attitudes towards technology.

More important were individual variables. Pupils with a positive technical self-concept (pupils who think that they already know quite a lot about technology) had better attitudes than those who do not. And 
Table 2

Results of Drawing Analyses

\begin{tabular}{|c|c|c|c|c|c|}
\hline \multirow[t]{2}{*}{ Category } & \multirow[t]{2}{*}{ Elements } & \multicolumn{2}{|c|}{$\begin{array}{c}\text { Boys } \\
(\mathrm{N}=139)\end{array}$} & \multicolumn{2}{|c|}{$\begin{array}{c}\text { Girls } \\
(\mathrm{N}=124)\end{array}$} \\
\hline & & 1 & $\%$ & $\mathrm{~N}$ & $\%$ \\
\hline \multirow[t]{14}{*}{ Products } & Radio, TV, video, CD player & 41 & 29.5 & 46 & 40.7 \\
\hline & Domestic equipment & 15 & 10.8 & 20 & 16.1 \\
\hline & Non-electrical equipment & 15 & 10.8 & 9 & 7.2 \\
\hline & Computer & 47 & 33.8 & 48 & 38.7 \\
\hline & Robot & 6 & 4.3 & 6 & 4.8 \\
\hline & Cars & 17 & 12.2 & 12 & 9.7 \\
\hline & Plane & 32 & 23.0 & 7 & 5.6 \\
\hline & Boat & 8 & 5.8 & 2 & 1.6 \\
\hline & Space travel & 18 & 12.9 & 3 & 2.4 \\
\hline & Bike & 3 & 2.1 & 5 & 4.0 \\
\hline & Tools & 2 & 1.4 & 2 & 1.6 \\
\hline & Machines & 8 & 5.8 & 9 & 7.2 \\
\hline & Building & 14 & 10.1 & 2 & 1.6 \\
\hline & Rest & 9 & 6.5 & 12 & 9.7 \\
\hline \multirow[t]{5}{*}{ Process } & A man is busy & 20 & 14.4 & 12 & 9.7 \\
\hline & A woman is busy & 1 & 0.7 & 11 & 8.9 \\
\hline & Something is being made & 17 & 12.2 & 14 & 11.3 \\
\hline & Something is being invented & 2 & 1.4 & 3 & 2.4 \\
\hline & Something is being repaired & 2 & 1.4 & 2 & 1.6 \\
\hline \multirow{8}{*}{ Evaluation } & Dangerous & 17 & 12.2 & 5 & 4.0 \\
\hline & Not dangerous & 20 & 14.3 & 30 & 24.2 \\
\hline & Difficult & 19 & 13.7 & 13 & 24.2 \\
\hline & Easy & 10 & 7.1 & 15 & 12.1 \\
\hline & Important & 35 & 25.1 & 19 & 15.3 \\
\hline & Unimportant & 5 & 3.6 & 4 & 3.2 \\
\hline & Nice/interesting & 25 & 17.9 & 22 & 17.7 \\
\hline & Not nice/boring & -- & -- & 6 & 4.8 \\
\hline \multirow{5}{*}{ Place } & School & 10 & 7.1 & 11 & 8.9 \\
\hline & Factory (workplace) & 31 & 24.5 & 18 & 14.5 \\
\hline & Home & 52 & 37.5 & 75 & 60.4 \\
\hline & Street & 28 & 20.1 & 15 & 12.0 \\
\hline & Space & 24 & 17.2 & 3 & 2.4 \\
\hline \multirow[t]{3}{*}{ Fantasy } & Future & 19 & 13.7 & 6 & 4.8 \\
\hline & Daily life & 69 & 49.6 & 81 & 65.3 \\
\hline & Old technology & 4 & 2.9 & 3 & 2.4 \\
\hline
\end{tabular}

the same can be said for ambition; those with a technical ambition appeared to have a more positive attitudes towards technology.

The variable Home Environment had a moderately postive influence on the attitude towards technology. Having played with technical toys and having a variety of tools is more important (correlates higher with the scores on the scales) than having parents with technical professions.

The relative influence of separate variables was investigated by means of multiple regression. Forty percent of the score on the AB-scales was explained by the following predictors:

1. Concept

2. Gender

3. Ambition

4. Self-Concept
$20 \%$

$9 \%$

$5 \%$

$2 \%$ 
Table 3

Kruskal's Coefficient Gamma Between Scale Scores and Variables

\begin{tabular}{lcccccccc}
\hline & Int. & Rol. & Con. & Dif. & Sch. & Car. & Soc. Skil.* \\
\hline & & & & & & & & \\
Gender & .52 & -.34 & .18 & .08 & .49 & .47 & -.32 & -.21 \\
Ambition & .88 & -.24 & .28 & .16 & .87 & .98 & -.43 & -.28 \\
Self-Concept & .84 & -.11 & .41 & .14 & .75 & .73 & -.67 & -.44 \\
Home Environment & .39 & -.06 & .24 & .07 & .39 & .31 & -.17 & -.30 \\
School Choice & .08 & -.06 & .07 & .07 & .09 & .10 & -.10 & -.02 \\
School Experienc & .05 & -.03 & .03 & .02 & .04 & .03 & -.02 & -.02 \\
& & & & & & & & \\
\hline
\end{tabular}

* Int=Interest, Rol=Role Pattern, Con=Consequences,

Dif=Difficulty, Sch=School, Car=Career, Soc=Society, Skil=Skills

$\begin{array}{llr}\text { 5. } & \text { Home Environment } & 2 \% \\ \text { 6. } & \text { Teacher Attitude } & <1 \% \\ \text { 7. } & \text { School Choice } & <1 \% \\ \text { 8. } & \text { School Experience } & <1 \%\end{array}$

From a path analysis with three variables, Gender, Affect (score on AB-scales), and Concept (score on C-scales), it appears that Concept influences Affect and not the other way around (see Figure 3). The total covariation between Concept and Affect (-.41) may be split up in a causal part (-.34) and a non-causal part (-.07). The model also shows that apart from Gender there are other major latent influences. This result means that a good concept of technology corresponds with a positive feeling about technology.

$\begin{array}{lllll}\text { GENDER } & -.19 & \text { CONCEPT } & -.34 & \text { AFFECT }\end{array}$

Figure 3. Path-coefficients Gender, Concept and Affect

Implications for Teacher Education at the Primary Level (age 4 -12)

From the perspective of attitude-formation, it is important to start technology education at an early age. This means that it is appropriate to pay attention to technology in the initial training of primary school teachers and/or as part of an inservice training. Pupils' should be taught a "broad concept of technology," because there is a positive relation between having a broad concept of technology and positive affection towards technology. A broad concept of technology means teaching different aspects of technology of which the relation between technology and society is important. It is necessary that pupils experience that technology is more than equipment and transportation. It is necessary for them to experience that technology is around them. Pupils must have a chance to deal with products of technology, and also to produce technology. If it is not possible to teach technology as a separate subject, it should be possible to develop "1001 examples" of practical applications that can be used or integrated in the existing curriculum.

\section{References}

Breakwell, G. M., et al. (1986). Attitudes to new technology. Current Psychological Research and Review, 5, 34-47.

Cohen, L., \& Manion, L. (1980). Research methods in education. London: Croom Helm.

de Klerk Wolters, F. (1989). The attitudes of pupils towards technology. Dissertation (in press) Eindhoven Univerity of Technology.

Gardner, P. L. (1975). Attitudes to science: A review. Studies in Science Education, 2, 1-41. 
Knulst, W., \& van Beek, P. (1988). Publiek en techniek. Den Haag: Sociaal Cultureel Planbureau.

Mokken, R. J. (1970). A theory and procedure of scale analysis, with applications in political research. Den Haag: Mouton \& Company.

Moore, J. (1987a). A picture questionnaire for investigating concepts of technology. Report of the PATT-2 Conference, Eindhoven.

Moore, J. (1987b). A technique for discovering young pupils' ideas about technology. CASTME Journal, 7(1), 1-10.

Mottier, I. (1986). Context of research, outcomes of the discussion. Report PATT-1 workshop, What do girls and boys think of technology? J. H. Raat and M. J. de Vries (ed). Eindhoven University of Technology.

Raat, J. H., \& de Vries, M. J. (1986). What do girls and boys think of technology? Report PATT-1 workshop. Eindhoven University of Technology.

Raat, J. H., de Klerk Wolters, F., \& de Vries, M. J. (1989). Pupils' Attitude Towards Technology, UNESCO-monography. (in press)

Rennie, L. J. (1988). How can we make technology interesting for girls. Report PATT-3 Conference, 2, 397-415. Eindhoven University of Technology.

Smail, B., \& Kelly, A. (1984). Sex differences in science and technology among 11-year-old schoolchildren: 1-cognitive and 2-affective. Research in Science \& Technological Education, 2(1 \& 2).

Schibeci, R. A. (1984). Attitudes to science: An update. Studies in Science Education, 11, 26-59.

Todd, R. D. (1986). Technology literacy: An international perspective. In Technology Education Symposium No. 8 Proceedings, 63-70. Roanoke VA. 